diminuição do infiltrado inflamatório e ausência de glândulas sebáceas. Em Akitas é descrito o crescimento piloso, durante o curso da doença, porém não dos subpelos, principalmente na região dorsal média. Cita-se que a progressão da doença é uma variável individual, mas possivelmente a variação temporal é associada a capacidade individual de regenerar as glândulas. Relata-se o aparecimento dos primeiros sinais desta doença em Akitas após episódios estressantes tais como doenças anteriores e cirurgias, e até mesmo o uso anterior de glicocorticóides. Assim, é interessante notar que o quadro clínico do primeiro animal se iniciou após realização de OSH, houve destruição das glândulas sebáceas, e a condição do pelame melhorou após o uso de humidificantes. $\mathrm{O}$ segundo caso foi observado em um cào, macho, Akita, com 3 anos de idade apresentado pápulas, descamação severa e lesões crostosas bilaterais e simétricas em região infra-orbitária e no tronco. Foram realizadas biópsias cutâneas por punch das lesões, que no exame microscópico revelaram em camada córnea hiperqueratose ortoqueratótica e paraqueratose focais. Os folículos pilosos apresentaram hiperqueratose ortoqueratótica pilar. Em região de anexos cutâneos observase intensa reaçào inflamatória linfo-histiocítica em região de glândulas sebáceas com destruição destas. As características clínicas e histopatológicas deste caso correspondem a adenite sebácea em fase aguda da doença, em que ocorre severo reação inflamatória linfo-histiocítica que tem como alvo as glândulas sebáceas, levando a sua completa destruição. Não foi possível o acompanhamento clínico do caso.

\title{
27 - Displasia folicular dos pêlos negros. Relato de caso
}

Cunha, F. M. ${ }^{\text {; }}$;ilveira, L. M. G. ${ }^{2}$; Perrone, E. A. ${ }^{3}$; Ferrigno, C. R. A. ${ }^{4}$; Futema, F. ${ }^{5}$
1- Professor Adjunto I de Clínica Médica da Faculdade de Medicina Veterinária da Universidade Paulista, São Paulo-SP

2 - Professor Adjunto I de Clínica Cirúrgica da Faculdade de Medicina Veterinária da Universidade Paulista, São Paulo-SP

3 - Professor Adjunto II de Patologia Especial da Faculdade de Medicina Veterinária da Universidade Paulista, São Paulo-SP

4 - Professor Doutor - Departamento de Cirurgia da Faculdade de Medicina Veterinária e Zootecnia da Universidade de São Paulo, São Paulo-SP

5 - Professor Adjunto II de Anestesiologia da Faculdade de Medicina Veterinária da Universidade Paulista, São Paulo-SP

Displasia folicular dos pêlos negros é uma desordem dermatológica hereditária de ocorrência incomum, observada em cães malhados (coloração preta e branca), puros de raça ou mestiços. Os animais afetados exibem hipotricose ou alopecia nas áreas corpóreas de pelagem negra, com preservação das regiões de pêlos brancos. O diagnóstico é baseado na anamnese, sinais clínicos e achados dermatohistopatológicos. Não há tratamento efetivo para tal condição $\mathrm{e}$ embora o distúrbio seja considerado apenas estético, a utilização de cães acometidos no serviço reprodutivo deverá ser desencorajada. Um cão sem raça definida, bicolor (preto $\mathrm{e}$ branco), fêmea, 17 anos de idade, foi atendido junto ao serviço de Clínica Médica do Hospital Veterinário da Universidade Paulista, com histórico de ausência permanente de pêlos negros, constatada pelo proprietário desde os primeiros meses de vida do animal. Ao exame físico, evidenciou-se alopecia completa e seletiva de porções negras do pelame acompanhada de descamação discreta, sem indícios macroscópicos da existência de alterações infecciosas e/ou inflamatórias concomitantes. As áreas de pêlos brancos apresentavam-se inalteradas. Procedeu-se a colheita de fragmento de tecido cutâneo para posterior análise histopatológica, a qual revelou atrofia epidérmica, folículos pilosos irregulares e preenchidos por queratina e incontinência pigmentar evidente, sem evidência de inflamação adjacente. Os dados colhidos na anamnese e exame físico aliados às informações fornecidas pelo estudo dermatohistopatológico permitiram a confecção do diagnóstico de displasia folicular dos pêlos negros. O cão foi submetido à terapia antiseborréica paliativa e seu proprietário foi instruido com informações pertinentes. 